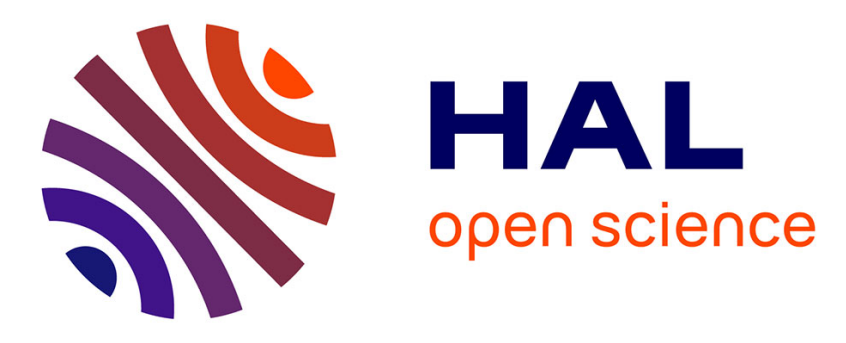

\title{
The role of the microstructure and defects on crack initiation in 316L stainless steel under multiaxial high cycle fatigue
}

\author{
Raphaël Guerchais, Franck Morel, Nicolas Saintier
}

\section{To cite this version:}

Raphaël Guerchais, Franck Morel, Nicolas Saintier. The role of the microstructure and defects on crack initiation in 316L stainless steel under multiaxial high cycle fatigue. Fatigue 2014:11th International Fatigue Congress, Mar 2014, Melbourne, Australia. pp.815-820, 10.4028/www.scientific.net/AMR.891-892.815 . hal-01082940

\section{HAL Id: hal-01082940 \\ https://hal.science/hal-01082940}

Submitted on 14 Nov 2014

HAL is a multi-disciplinary open access archive for the deposit and dissemination of scientific research documents, whether they are published or not. The documents may come from teaching and research institutions in France or abroad, or from public or private research centers.
L'archive ouverte pluridisciplinaire HAL, est destinée au dépôt et à la diffusion de documents scientifiques de niveau recherche, publiés ou non, émanant des établissements d'enseignement et de recherche français ou étrangers, des laboratoires publics ou privés. 


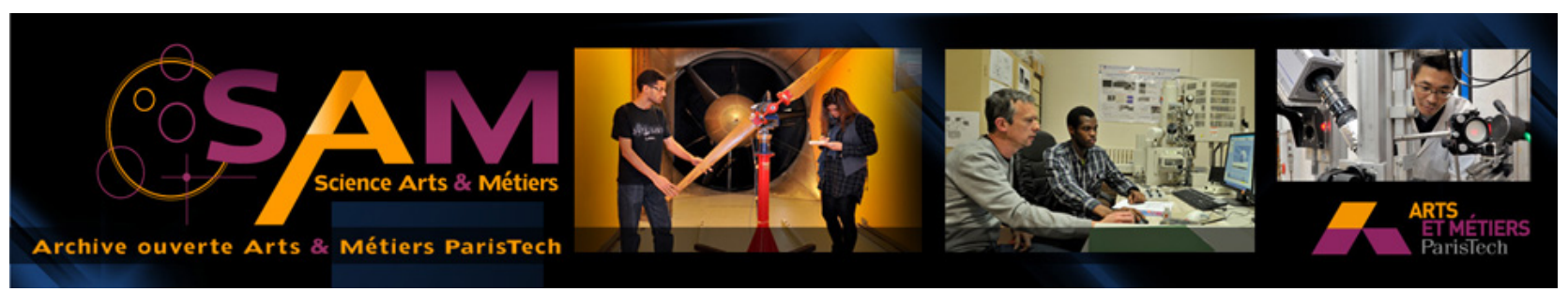

\section{Science Arts \& Métiers (SAM)}

is an open access repository that collects the work of Arts et Métiers ParisTech researchers and makes it freely available over the web where possible.

This is an author-deposited version published in: http://sam.ensam.eu

Handle ID: .http://hdl.handle.net/10985/8903

\section{To cite this version :}

Raphaël GUERCHAIS, Franck MOREL, Nicolas SAINTIER - The role of the microstructure and defects on crack initiation in $316 \mathrm{~L}$ stainless steel under multiaxial high cycle fatigue - In: Fatigue 2014:11th International Fatigue Congress, Australia, 2014-03 - 11th International Fatigue Congress - 2014 


\title{
The role of the microstructure and defects on crack initiation in $316 \mathrm{~L}$ stainless steel under multiaxial high cycle fatigue
}

\author{
Raphaël GUERCHAIS ${ }^{1,2, a}$, Franck MOREL ${ }^{1, b}$ and Nicolas SAINTIER ${ }^{2, c}$ \\ ${ }^{1}$ Arts et Métiers PARISTECH, LAMPA, Angers, France \\ ${ }^{2}$ Arts et Métiers PARISTECH, I2M UMR CNRS 5295, Talence, France

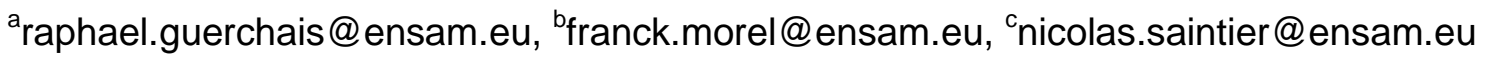

\begin{abstract}
Keywords: High Cycle Fatigue, Multiaxial Loading, 316L, Finite Element Analysis, Polycrystalline Aggregate, Defects, Probabilistic Fatigue Criterion.
\end{abstract}

\begin{abstract}
The aim of this study is to analyse the influence of both the microstructure and defects on the high cycle fatigue behaviour of the $316 \mathrm{~L}$ austenitic stainless steel, using finite element simulations of polycrystalline aggregates. High cycle fatigue tests have been conducted on this steel under uniaxial (push-pull) and multiaxial (combined in-phase tension and torsion) loading conditions, with both smooth specimens and specimens containing artificial semi-spherical surface defects. 2D numerical models, using a cubic elastic constitutive model, are created to determine the degree of heterogeneity of the local stress parameters as a function of the defect size. This has been done for one microstructure using several orientation sets generated from the initial texture of the material. The grains are explicitly modelled and the anisotropic behaviour of each FCC crystal is described by the generalized Hooke's law with a cubic elasticity tensor. From the simulations carried out with different defect sizes and orientation sets that are representative of the real texture of the tested material, statistical information regarding mesoscopic mechanical fields provides useful insight into the microstructural dependence of the driving forces for fatigue crack nucleation at the mesoscopic scale (or the scale of individual grains). The results in terms of the stress fields and fatigue crack initiation conditions are determined at both the mesoscopic and macroscopic scales. The results from these FE models are used along with an original probabilistic mesomechanics approach to quantify the defect size effect. The resulting predictions, which are sensitive to the microstructure, include the probability distribution of the high cycle fatigue strength.
\end{abstract}

\section{Introduction}

In ductile alloys like austenitic stainless steels, fatigue crack initiation is most of the time caused by localized deformation in slip bands. As the local stress and strain fields in a grain is strongly dependent on its orientation, the distribution of the plastic glide in a polycrystalline aggregate composed of many crystals is non-homogeneously distributed. This heterogeneous distribution of the plastic glide is much more pronounced in High Cycle Fatigue (HCF) than in Low Cycle Fatigue (LCF). The classical macroscopic HCF models [1,2] where the critical variables are function of the macroscopic stress, though sometimes powerful design tools, fail to reflect this basic feature of the HCF damage.

The previous analysis holds true for smooth specimen with no stress or strain concentrations. When a notch is introduced, although the bulk of the component may undergo macroscopic elastic deformation, the highly stressed region in the vicinity of the notch root may experience significant plastic deformation. However, in many HCF situations, even if the favorably oriented grains at the notch root undergo cyclic plasticity, the peak notch root equivalent stress is below the macroscopic yield strength, once an elastic shakedown state has been reached. Even the most promising macroscopic multiaxial models incorporating the beneficial effect of the stress gradient to explain crack initiation at notch root [2] lack explicit consideration of intrinsic length scales of grains. This is particularly true for the smallest notch root of the order of the grain size. 
This paper focuses on a microstructure-sensitive method that involves explicit modeling of elastic behavior of individual grains in polycrystalline metals and alloys under HCF conditions, with emphasis on notch sensitivity under multiaxial loading conditions. 2D numerical models, using a cubic elastic constitutive model, are created to determine the degree of heterogeneity of the local stress parameters as a function of the defect size. The results from these FE models are used along with an original probabilistic mesomechanics approach to quantify the defect size effect.

\section{Experimental multiaxial fatigue tests: effect of artificial defects}

Characterization of 316L stainless steel. The austenitic stainless steel used for this study is an AISI 316L M25W steel produced by consumable electrode remelting. It is often used for the manufacturing of orthopaedic implants, hip prosthesis, endomedulary nails, spine systems, rods and screws. Its chemical composition is given in table 1 and the mechanical properties are gathered in Table 2. Observations by Scanning Electron Microscopy (SEM) and by Electronic Back Scatterring Diffraction (EBSD) techniques showed that the average grain size is $14 \mu \mathrm{m}$ (considering the twin boundaries) and a lot of grains showed annealing twins. Let us notice that the austenite phase being rather stable (high Ni content), no delta ferrite was observed. The steel was provided as bars of 40 $\mathrm{mm}$ in diameter and $1,2 \mathrm{~m}$ in length, from which all the fatigue specimens were machined. Fig. 1 illustrates the sketch of the fatigue specimen used in the present investigation. After machining, the specimens were carefully mechanically polished to get a "mirror-like" finish.

Table 1 : Chemical composition of AISI 316L M25W steel (wt.\%)

\begin{tabular}{cccccc}
\hline Element & $\mathrm{C}$ & $\mathrm{Cr}$ & $\mathrm{Ni}$ & $\mathrm{Mo}$ & $\mathrm{Mn}$ \\
\hline Wt.\% & 0.02 & 18.96 & 15 & 3.01 & 1.87 \\
\hline
\end{tabular}

Table 2 : Tensile properties of AISI 316L M25W steel

\begin{tabular}{cccc}
\hline $\begin{array}{c}\text { Young's } \\
\text { modulus [GPa] }\end{array}$ & $\begin{array}{c}\text { Poisson } \\
\text { ratio }\end{array}$ & $\begin{array}{c}\text { Yield strength } \\
0.2 \%[\mathrm{MPa}]\end{array}$ & $\begin{array}{c}\text { Ultimate strength } \\
{[\mathrm{MPa}]}\end{array}$ \\
\hline 194 & 0.284 & 346 & 644 \\
\hline
\end{tabular}
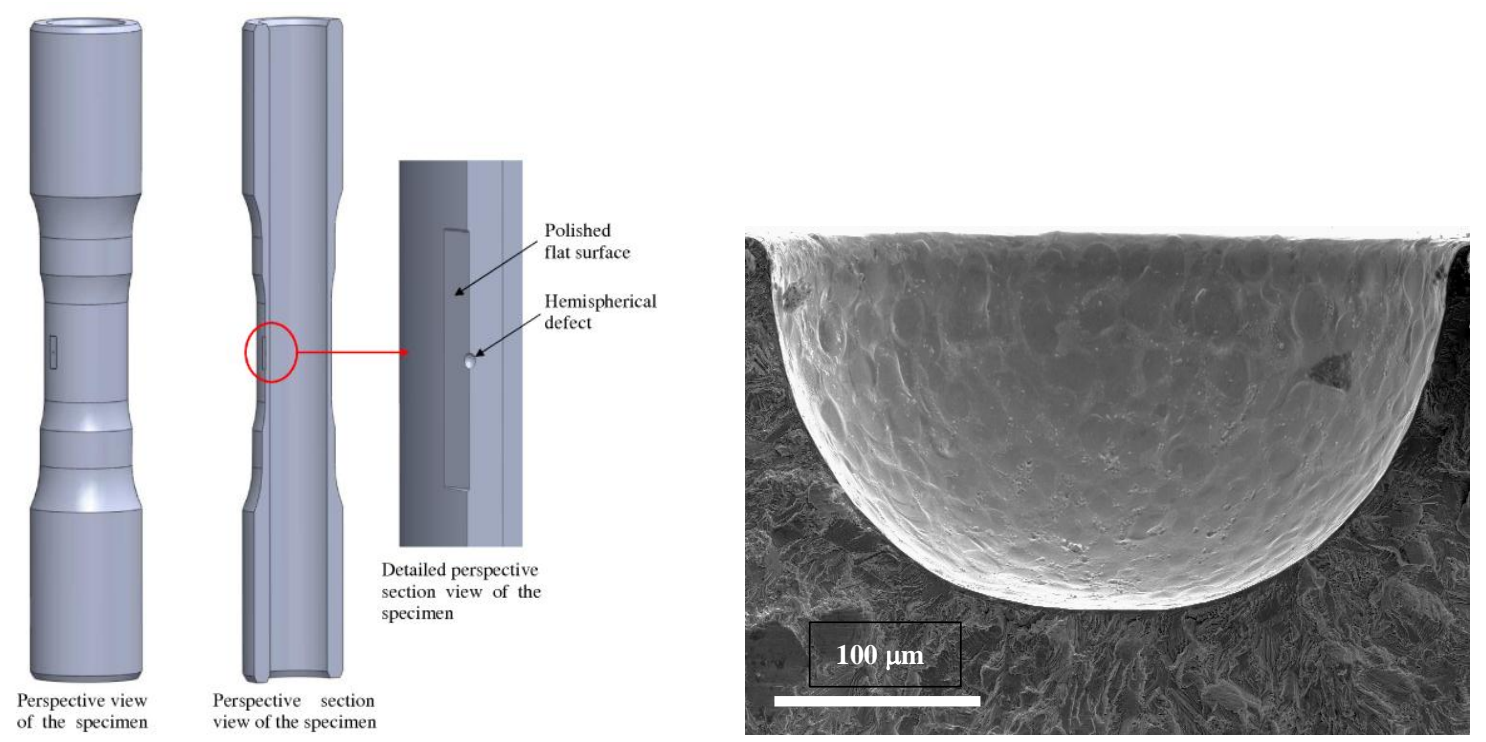

Fig. 1. Hollow biaxial specimens - Position of the artificial defect on the gauge length and geometry of a $300 \mu \mathrm{m}$ artificial defect.

Fatigue tests. Fatigue tests were performed under uniaxial and multiaxial loading conditions on cylindrical hollow specimens. They were carried out at a frequency of $10 \mathrm{~Hz}$ at room temperature and in the air environment under load and/or torque control (load and torque ratios $\mathrm{R}=-1$ ) on the same Instron biaxial servohydraulic machine. All the fatigue results conducted are gathered in Fig. 
2 for different biaxial ratios. To get an estimation of the fatigue limits under several loading conditions, it was decided to use a step method (instead of a more time consuming staircase method for instance). This method consists in loading a specimen at an initial stress level up to $2.10^{6}$ cycles and in cycling again the same specimen at a higher stress amplitude if the failure is not reached during the first step. For each loading condition and each defect size, three specimens are used to determine two stress amplitudes: $\Sigma_{\mathrm{ij}, \mathrm{a}, \mathrm{NF}}$ and $\Sigma_{\mathrm{ij}, \mathrm{a}, \mathrm{F}}$ corresponding respectively to the maximum stress amplitude tested for which no macroscopic fatigue crack were observed and to the minimum stress amplitude tested for which no specimen has withstood $2.10^{6}$ cycles without the initiation of a macroscopic fatigue crack. The average fatigue limit was then calculated as the average of $\Sigma_{\mathrm{ij}, \mathrm{a}, \mathrm{NF}}$ and $\Sigma_{\mathrm{ij}, \mathrm{a}, \mathrm{F}}$.

Artificial defect and multiaxial effect. In order to study the impact of notch and biaxiality on the fatigue strength, some hemispherical defects (Fig. 1), ranging from 100 to $500 \mu \mathrm{m}$ in size, are introduced at the surface of hollow specimens by means of Electric Discharge Machining (EDM). This technique was found to get reproducible defects of different size. Fig. 2 depicts $\Sigma_{a}$ versus the defect size D (defect diameter) for all the loading scenarii and defect sizes. This graph, gathering all the experimental results, clearly shows the detrimental influence of the biaxial ratio $\Sigma_{12, \mathrm{a}} / \Sigma_{11, \mathrm{a}}$ on the fatigue strength. A biaxial ratio $\Sigma_{12, \mathrm{a}} / \Sigma_{11, \mathrm{a}}$ increase (purely reversed tension: 0 , combined tension and torsion: 0.5 , purely reversed tension: $\infty$ ) leads to a drop of the fatigue limit. For a biaxial ratio of $\Sigma_{12, \mathrm{a}} / \Sigma_{11, \mathrm{a}}=0.5$, and whatever the defect size, the combined loading lies between the torsion and the push-pull results.

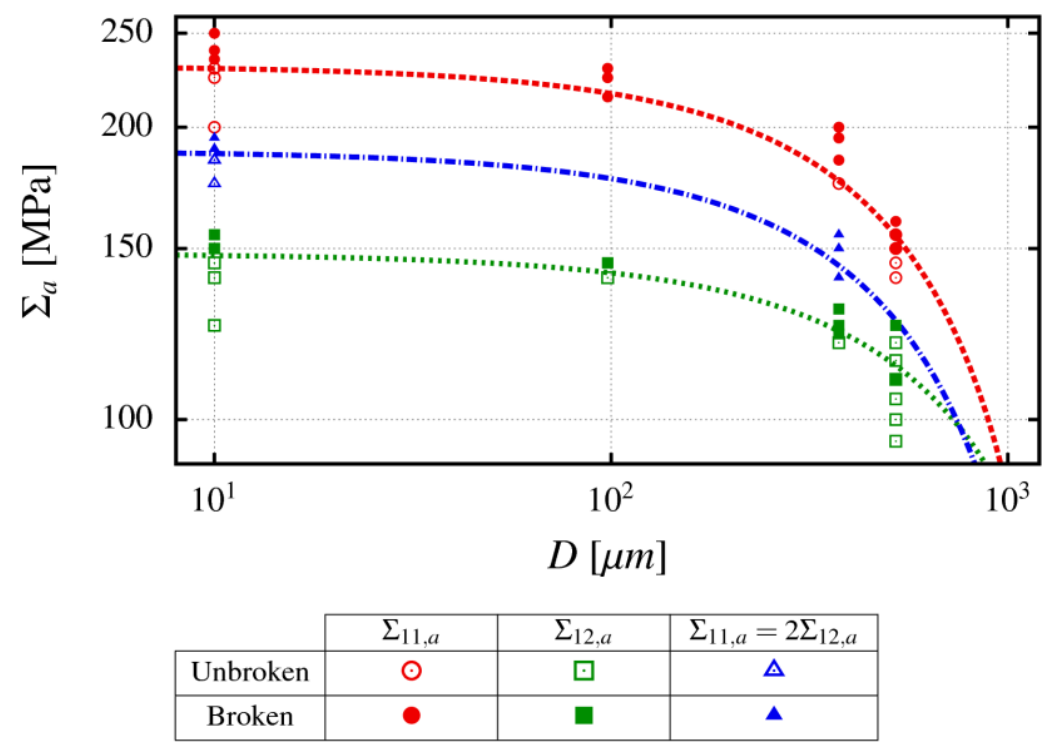

Fig. 2. 316L M25W experimental fatigue behaviour under different biaxial loading conditions Effect of the defect size and the biaxial ratio $\Sigma_{12, a} / \Sigma_{11, \mathrm{a}}$.

\section{Computational micromechanics}

Constitutive model. A generalized Hooke's law with a cubic elasticity tensor is used with small strain assumption. Each grain is considered to be a single crystal and the displacement fields are assumed to be continuous at grain boundaries. Cubic elasticity is assigned to every grain by means of 3 coefficients $\mathrm{C}_{1111}, \mathrm{C}_{1122}, \mathrm{C}_{1212}$ characteristic of the elastic anisotropic behaviour of FCC crystals and determined by Huntington [3]. The orientation of each crystal with respect to the reference frame is defined by a triplet of Euler angles.

Finite element model. Using the constitutive model outlined in the previous section, twodimensional (2D) finite element calculations are conducted for synthetic microstructures. To reduce computational time and to get a simplified description of the notch, the notch geometry is decomposed into two regions (Fig. 3): an outermost region, far from the notch root, where an isotropic elastic model is used and the notch root region which employs the cubic elastic model. 
With the size of the polycrystalline aggregate chosen, the smooth microstructure contains 3265 crystals in order to respect the average grain size. The finite element mesh of the synthetic microstructure CAD is obtained using Gmsh [4]. Three-node triangular finite elements, with linear interpolation and generalized plane strain hypothesis, are used and each crystal are discretized in average with 100 elements. For each defect size studied, one polycrystalline aggregate and ten different orientations set are employed. Orientation sets are composed by triplet of Euler angles selected to be representative of the texture measured in the as-received material. As a result, the response of 10 different realizations is investigated per defect size. The numerical simulations are conducted with ZeBuLoN FE software.

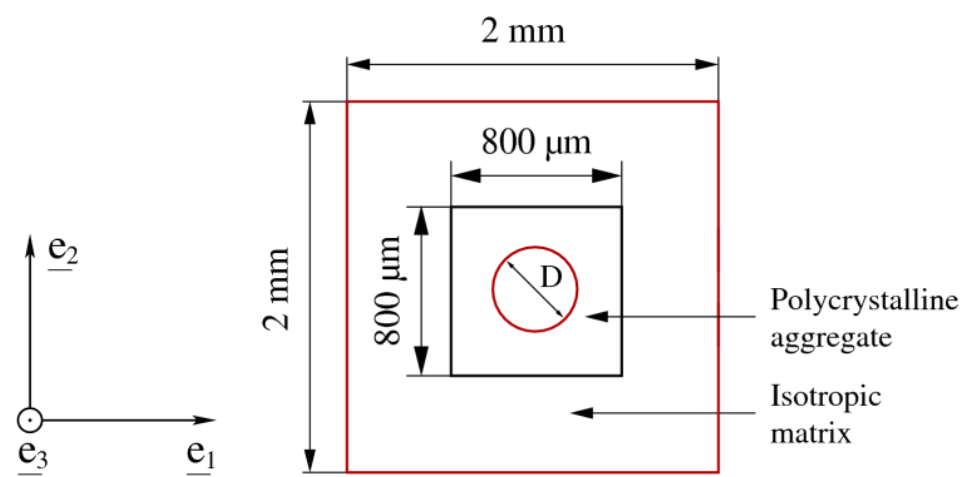

(a) Schematic representation of the global geometry

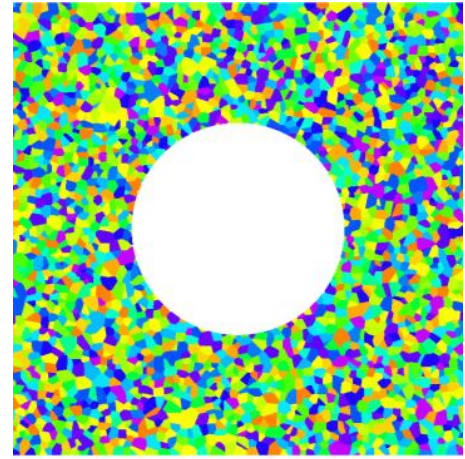

(b) Microstructure geometry

Fig. 3. Notch geometry decomposition in two regions: polycrystalline aggregate and matrix.

Microstructure-sensitive probabilistic fatigue model. As pointed out in the introduction, the microslip among grains is known as the main driving force of fatigue crack initiation in ductile alloys. It is hence natural to assume that the metallic polycrystals investigated in this study exhibit shear-dominated fatigue crack initiation. This crack initiation behaviour is assumed to be adequately accounted for by means of two resolved stresses: the shear stress and the normal stress both acting on a slip plane.

Several studies carried out by the present authors [5,6] clearly showed that these two local mechanical parameters are strongly affected by the crystal orientation within the polycrystalline aggregate. The resulting statistical distributions over an arbitrary elementary volume of these quantities give a potential explanation of the experimental scatter of the macroscopic fatigue response usually observed in HCF. Nonetheless, the fatigue crack initiation remains a very complex mechanism and the idealized modeling of the microstructure proposed in this work seems too partial and unable to reflect all the local material heterogeneities. For these reasons, the formation of a fatigue crack on the scale of a single grain will be assumed to be governed not only by the mesoscopic shear and normal stresses acting on a slip plane (and deduced from the FE computation) but also affected by a statistical distribution of the crack initiation threshold representative of the local microstructural heterogeneities.

More practically, a fatigue crack is likely to appear in a grain if the shear stress amplitude acting on the most stressed plane exceeds a threshold. The latter is supposed to be a random variable following a Weibull distribution characterized by a shape parameter $m$ and a scale parameter $\tau_{0}$. Hence, the initiation probability on a slip system can be expressed by:

$$
P_{F n}=P\left(\tau_{a} \geq \tau_{a}^{t h}\right)=1-\exp \left[-\left(\frac{\tau_{a}}{\tau_{0}}\right)^{m}\right] .
$$

The normal stress is assumed to modify the initiation conditions by affecting the scale factor. More exactly, the normal stress amplitude $\sigma_{n, a}$ and mean $\sigma_{n, m}$ acting on the slip plane of normal $\underline{n}$ occur in the final $\tau_{0}$ expression through a triaxiality factor $\sigma_{n, a} / \tau_{a}$ and a mean dependence $\sigma_{n, m}$ : 


$$
\tau_{0}=\tau_{0}^{\prime} \frac{1-\gamma \sigma_{n, m}}{1+\alpha\left(\sigma_{n, a} / \tau_{a}\right)} \tau_{0}=\tau_{0}{ }^{\prime} \frac{1 \gamma \sigma_{n, m}}{1+\alpha \frac{\sigma_{n, a}}{\tau_{a}}} \cdot \frac{b_{a}}{a_{b}}
$$

The initiation probability in a grain $P_{F g}$ is supposed to correspond to the maximum among the failure probabilities of its slip planes. Finally, the failure probability of the polycrystalline aggregate $P_{F a}$ is computed according to the weakest-link hypothesis:

$$
1-P_{F a}=\prod_{g=1}^{N_{g}}\left(1-P_{F g}\right) 1 \quad P_{F a}=\prod_{g=1}^{N_{g}}\left(\begin{array}{ll}
1 & P_{F g}
\end{array}\right) .
$$

\section{Results and discussion}

Local field distributions. Fig. 4 gathers, for two defect sizes $\mathrm{D}(0 \mu \mathrm{m}$ and $300 \mu \mathrm{m})$, the response of each slip plane deduced from the FE simulations of one realization (one microstructure and one orientation set), in terms of $\tau_{\mathrm{a}} / \sigma_{\mathrm{n}, \mathrm{a}}$. The loading amplitude $\left(\Sigma_{11, \mathrm{a}}\right.$ and $\left.\Sigma_{12, \mathrm{a}}\right)$ applied to the polycrystalline aggregate corresponds to the experimental average fatigue limit in every case.

These results reflect the large scatter of $\tau_{\mathrm{a}}$ and $\sigma_{\mathrm{n}, \mathrm{a}}$. Moreover, the distributions of these two mesoscopic mechanical quantities are affected by the anisotropic elastic behavior. Indeed, for instance in the case of fully reversed tension with $\mathrm{D}=0 \mu \mathrm{m}$, the maximum values reached by $\tau_{\mathrm{a}}$ and $\sigma_{\mathrm{n}, \mathrm{a}}$ increased respectively by $18 \%$ and $45 \%$ when compared to the isotropic elastic case. It can also be observed that these maximum values are significantly raised in the presence of a defect.

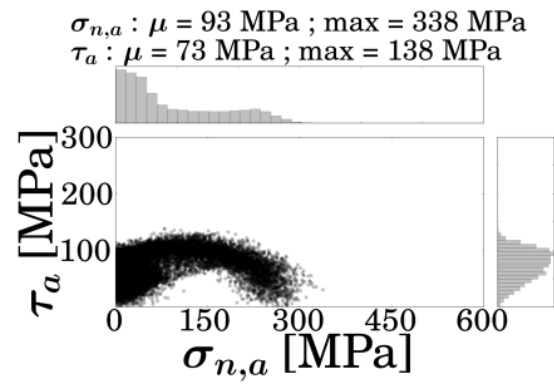

(a) Fully reversed tension,

$$
\mathrm{D}=0 \mu \mathrm{m}
$$

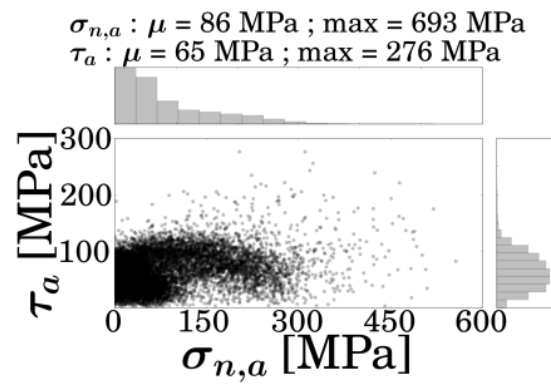

(d) Fully reversed tension, $\mathrm{D}=300 \mu \mathrm{m}$

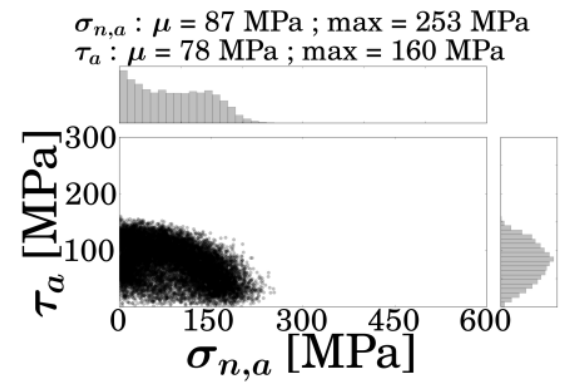

(b) Fully reversed torsion, $\mathrm{D}=0 \mu \mathrm{m}$

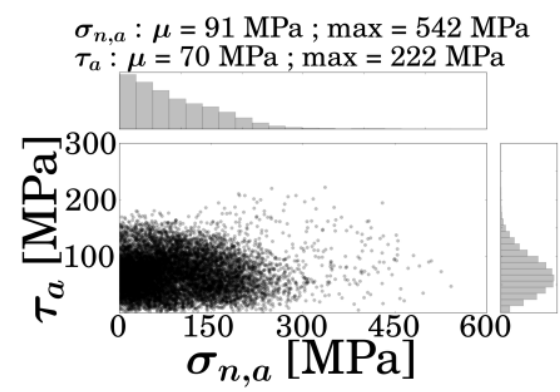

(e) Fully reversed torsion, $\mathrm{D}=300 \mu \mathrm{m}$

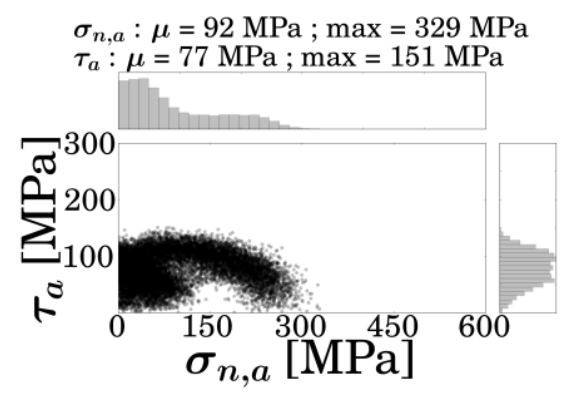

(c) Tension-Torsion in-phase, $\mathrm{D}=0 \mu \mathrm{m}$

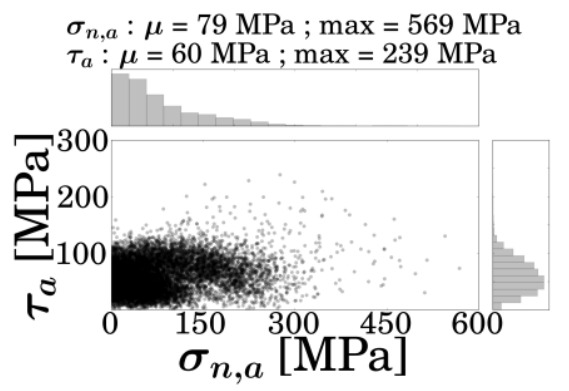

(f) Tension-Torsion in-phase, $\mathrm{D}=300 \mu \mathrm{m}$

Fig. 4. Mesoscopic stress response, in terms of $\tau_{\mathrm{a} /} \sigma_{\mathrm{n}, \mathrm{a}}$, of each slip planes.

Identification and predictions of the microstructure-sensitive probabilistic fatigue model. The identification of the parameters of the probabilistic fatigue criterion is based on the results of the FE simulations of smooth microstructures loaded, at the average fatigue limit, in fully reversed tension and in fully reversed shear. Except the shape parameter which is imposed $(\mathrm{m}=5)$, these parameters are identified such as $\mathrm{P}_{\mathrm{Fa}}=50 \%$ in average on the 10 realizations for each loading condition. 
The predictions of the criterion, for a given loading condition and defect size, are then computed by determining the loading amplitude which has to be applied to the microstructure so that $\mathrm{P}_{\mathrm{Fa}}=50 \%$ in average on the 10 realizations. The resulting predicted fatigue limits are presented in a KitagawaTakahashi diagram (Fig. 5) with the experimental data.

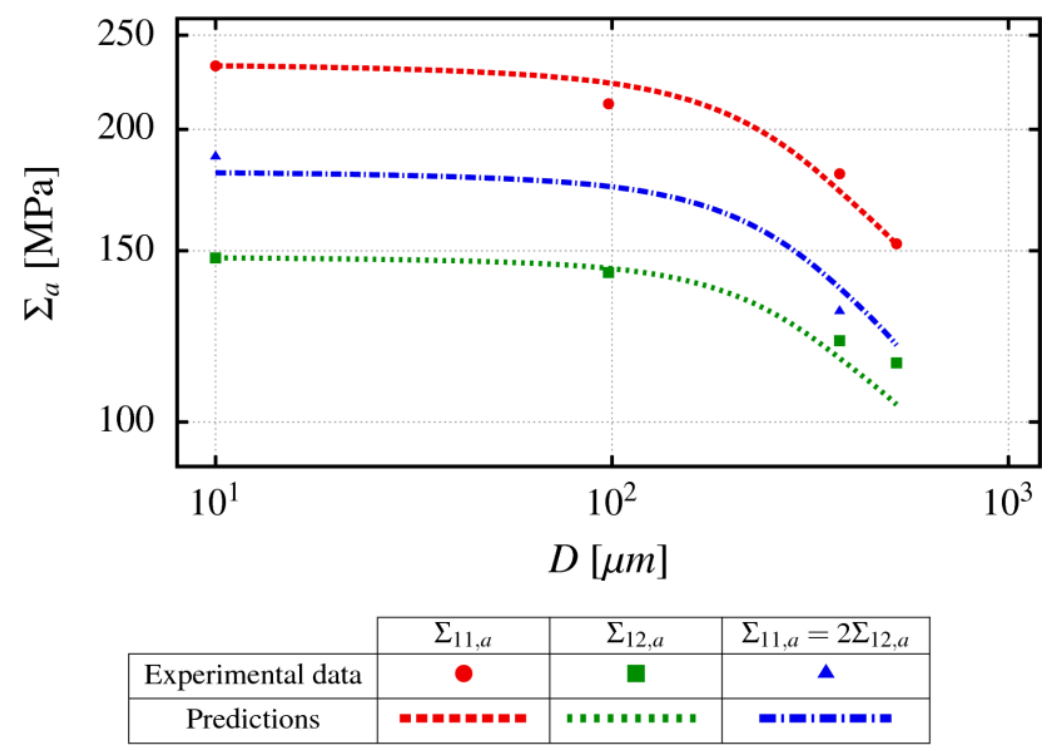

Fig. 5. Comparison between the predictions of the criteria and the experimental data for each defect size and for different biaxial ratios.

From this figure, it can be observed that the probabilistic fatigue model provides satisfactory predictions for loading condition and defect size considered. Indeed, the maximum error, encountered in fully reversed tension for a defect with $\mathrm{D}=500 \mu \mathrm{m}$, is lower than $10 \%$. In most cases, the error lies between $4 \%$ and $6 \%$.

\section{Conclusions}

The experimental fatigue tests conducted in this work have clearly demonstrated the detrimental effect of the increase in the biaxial ratio $\Sigma_{12, \mathrm{a}} / \Sigma_{11, \mathrm{a}}$ on the fatigue strength for a $316 \mathrm{~L}$ austenitic steel whatever the defect size considered. It has also been observed that, for a given defect size, the decrease of the fatigue limit is more important in tension than in torsion.

The numerical modeling employed in this study has highlighted that large scatter at the grain scale of relevant mechanical quantities. Moreover, the predictions provided by the proposed probabilistic fatigue model have shown a good agreement with the experimental fatigue limits.

\section{References}

[1] K. Dang-Van, Macro-micro approach in high-cycle multiaxial fatigue, in: D.L. McDowell, J.R. Ellis (Eds.), Advances in Multiaxial Fatigue, ASTM Special Technical Publication, 1993, pp. 120130.

[2] F. Morel, N. Huyen, Plasticity and damage heterogeneity in fatigue, Theoretical and Applied Fracture Mechanics. 49 (2008) 98-127.

[3] H.B. Huntington, The elastic constants of crystals, in: F. Seitz, D. Turnbull (Eds.), Solid State Physics (7), 1958, pp. 213-351.

[4] C. Geuzaine and J.-F. Remacle, Gmsh: A 3-D finite element mesh generator with built-in pre- and post-processing facilities, International Journal for Numerical Methods in Engineering. 19 (2009) 1309-1331. 
[5] C. Robert, N. Saintier, T. Palin-Luc, F. Morel, Micro-mechanical modelling of high cycle fatigue behaviour of metals under multiaxial loads, Mechanics of Materials. 55 (2012) 112-129.

[6] R. Guerchais, C. Robert, F. Morel, N. Saintier, Micromechanical study of the loading path effect in high cycle fatigue, to be published in International Journal of Fatigue. 